\title{
Endoscopic Ultrasound-Guided Choledochoduodenostomy for Biliary Drainage in Patients with Lower End Common Bile Duct Block: A Single-Center Experience
}

\begin{abstract}
Vikas Singla, Ritesh Prajapati, Shrihari Anil Anikhindi, Mandhir Kumar, Ashish Kumar, Praveen Sharma, Naresh Bansal, Anil Arora
\end{abstract}

Institute of Liver, Gastroenterology and Pancreaticobiliary Sciences, Sir Ganga Ram Hospital, New Delhi, India
Objective: Endoscopic ultrasound (EUS)-guided biliary drainage is evolving as an alternative technique in patients with failed endoscopic retrograde cholangiopancreatography. The objective of this study was to find out the outcome of EUS-guided choledochoduodenostomy in patients with malignant mid and lower end biliary obstruction with inaccessible papilla presenting at our center. Methods: The present study was a single-center prospective observational study. Data of all the patients who underwent choledochoduodensotomy from January 2014 to December 2015 were recorded. Outcome measures were technical success and clinical success. Technical success was defined as successful placement of stent in the biliary system; clinical success was defined as $50 \%$ reduction in bilirubin at 2 weeks. Complications during the procedure and follow-up were recorded. Results: A total of 10 patients underwent EUS-guided choledochoduodenostomy. Cause of biliary obstruction was pancreatic cancer in eight patients, two patients had carcinoma gallbladder with mid-common bile duct (CBD) block due to compression by metastatic lymph nodes, and one patient had ampullary carcinoma. Mean bilirubin value was $16.4 \mathrm{mg} / \mathrm{dL}( \pm 3.2 \mathrm{mg} / \mathrm{dL})$. Technical and clinical success were $100 \%$ and $90 \%$, respectively. No immediate procedure-related complication was noticed. Two patients had stent migration during the follow-up. Conclusion: EUS-guided choledochoduodenostomy is an effective and safe alternative for rescuing biliary drainage in patients with mid and lower end malignant CBD block with inaccessible papilla.

KEYWORDS: Endoscopic ultrasound, choledochoduodenostomy, common bile duct block

\section{INTRODUCTION}

$\mathcal{E}$ ndoscopic retrograde cholangiopancreatography (ERCP) is the established procedure for biliary drainage in patients with malignant biliary obstruction. ${ }^{[1]}$ Although the success rate of ERCP is more than $95 \%$, ERCP may not be possible in patients with tumor invasion of the duodenum or the major papilla and postsurgical cases. ${ }^{[2,3]}$ Percutaneous transluminal biliary drainage (PTBD) is a conventional alternative procedure in such conditions, but is associated with complications of pain, bile leak, bleeding, and possibility

\begin{tabular}{|l|l|}
\hline \multicolumn{2}{|c|}{ Access this article online } \\
\hline Quick Response Code: & Website: www.jdeonline.in \\
\hline
\end{tabular}

of permanent external drainage. ${ }^{[4]}$ Since endoscopic ultrasound (EUS)-guided bile duct puncture was described in $1996,{ }^{[5]}$ various reports regarding technical feasibility and complication rate of EUS-guided biliary drainage have been published. The potential benefits

\section{Address for correspondence: Dr. Vikas Singla, Institute of Liver, Gastroenterology and Pancreaticobiliary Sciences, Sir Ganga Ram Hospital, Rajinder Nagar, New Delhi - 110 060, India. E-mail: singlavikas1979@gmail.com}

This is an open access article distributed under the terms of the Creative Commons At tribution-NonCommercial-ShareAlike 3.0 License, which allows others to remix, tweak, and build upon the work non-commercially, as long as the author is credited and the new creations are licensed under the identical terms.

For reprints contact: reprints@medknow.com

How to cite this article: Singla V, Prajapati R, Anikhindi SA, Kumar M, Kumar A, Sharma P, et al. Endoscopic Ultrasound-Guided Choledochoduodenostomy for Biliary Drainage in Patients with Lower End Common Bile Duct Block: A Single-Center Experience. J Dig Endosc 2018;9:6-9. 
of EUS-guided drainage over PTBD are single-stage procedure and internal drainage. The technique is still evolving with different success rate and complication rates across the studies, which may depend on indication of the procedure, type of procedure chosen, and the accessories used. The present study is our experience with EUS-guided transduodenal drainage in patients with mid and lower end common bile duct (CBD) obstruction.

\section{Methods}

\section{Patients and methods}

The present study is a prospective study conducted at a single tertiary care referral center (Sir Ganga Ram Hospital, New Delhi, India). Data of all the patients undergoing endoscopic biliary drainage for malignant biliary obstruction from January 2014 to December 2015 were prospectively collected. All the patients with malignant biliary obstruction and unresectable disease based on computed tomography, magnetic resonance imaging and EUS findings, and inaccessible papilla due to duodenal narrowing were considered for EUS-guided choledochoduodenostomy (CD). Informed consent was obtained from all the patients after explaining the technique and possible complications of EUS-guided CDS.

\section{Technique of endoscopic ultrasound-CDS and stenting}

A single interventional endoscopist (VS) experienced in EUS, who has performed more than 1500 EUS-guided fine-needle aspirations (FNAs) and more than 50 EUS-guided drainage procedures, performed all the EUS-guided biliary drainage procedures. All patients received prophylactic antibiotics. Intervention radiologist was informed before starting procedure, for the need of percutaneous drainage if the procedure fails, or radiological management of complication.

All the procedures were performed in prone position under conscious sedation with midazolam and pentazocine. Procedures carried out in the prone position as fluoroscopic imaging was a part of the procedure. Previous studies have shown that it is technically easier and safer to perform in the prone position. ${ }^{[6]}$ EUS was performed with linear array echoendoscope (GFUCT180; Olympus Medical, Tokyo, Japan). Initial endoscopic surveillance was done to rule out duodenal lesions, precluding transduodenal drainage. CBD was focused from the first part of the duodenum, scope was turned counterclockwise, which would direct the probe and accessories toward liver hilum. In the first part of the duodenum, the echoendoscope was positioned in the long loop as it is the stable position. ${ }^{[7]}$ Before planning
EUS drainage, dilatation with controlled radial expansion balloon was not planned due to risk of perforation and bleeding. ${ }^{[8]}$ Transduodenal puncture of CBD was done with 19Gneedle (Echo Tip 19A; Cook Endoscopy, Winston Salem, NC, USA) [Figure 1a], stylet was withdrawn, position was confirmed with bile aspiration, contrast was injected and cholangiogram was obtained. Subsequently, $0.035 \mathrm{inch} / 450-\mathrm{cm}$ guidewire (Jagwire, Microvasive Endoscopy, Boston Scientific, Natick, MA, USA) was directed toward the intrahepatic radical, following which needle was withdrawn leaving wire in situ [Figure 1b]. Over-the-wire dilatation was performed with 6 Fr cystotome (Cysto Gastro Set; Endoflex, GmbH, Voerde, Germany) with coagulation current [Figure 1c], following which $6 \mathrm{~cm}$ fully covered self-expanding metal stent (Wallstent; Microvasive Endoscopy, Boston Scientific, Natick, MA, USA) was deployed, leaving $2 \mathrm{~cm}$ of stent in duodenum as a safeguard against internal migration in CBD [Figure 1d]. The entire procedure was performed under fluoroscopy. After the procedures, all the patients were admitted for $24-48 \mathrm{~h}$ and were monitored for signs of internal bleeding, duodenal leak, and cholangitis. If there was no complication, clear liquids were allowed next day.

\section{Inclusion and exclusion criteria}

The procedure was performed only in patients with proven malignancy with mid and lower end CBD block.

Exclusion criteria were pregnancy, major organ failure, large volume ascites, poor cardiovascular status, coagulopathy (international normalized ratio $>1.5$ ), thrombocytopenia (platelet counts $<50,000 / \mu \mathrm{L}$ ), and refusal to consent.

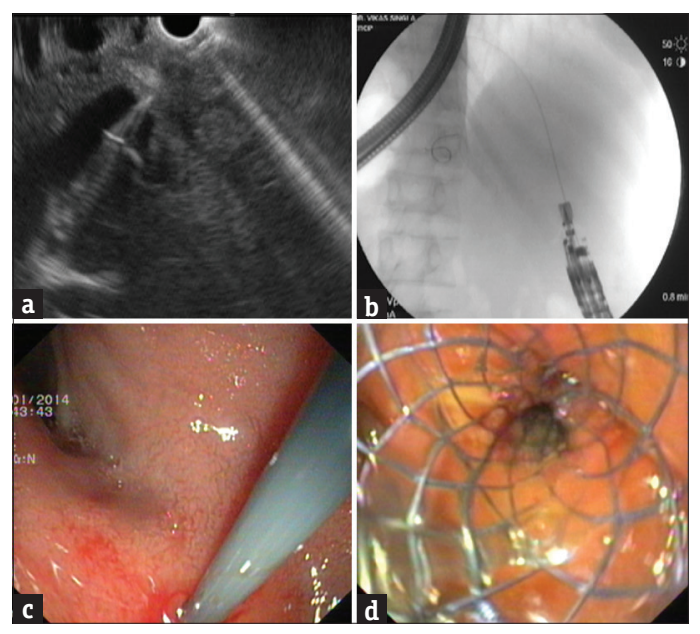

Figure 1: (a) Endoscopic ultrasound-guided transduodenal puncture of the common bile duct in suprapancreatic part. $19 \mathrm{G}$ needle seen in situ. (b) Fluoroscopic image of guidewire in common bile duct and left biliary system. (c) Dilatation of tract with 6 Fr cystotome with diathermy ring. (d) Self-expanding metal stent across the choledochoduodenostomy site. 


\section{Outcome measures: Success and complications}

Outcome measures were technical success and functional success. Technical success was defined as successful deployment of the stent in CBD. Clinical success was defined as a reduction in bilirubin value by $50 \%$ at 2 weeks compared with the preprocedural value. All the complications during the procedures and during follow-up were recorded. During and after the procedure, patients were monitored for complications of internal bleeding, bile leak, and pneumoperitoneum. After the discharge, patients were followed up for the evaluation of persistent successful biliary drainage. Cross-sectional imaging was done during follow-up if indicated.

\section{Results}

From January 2014 to December 2015, ten patients (6 males) underwent EUS-guided CDS [Table 1]. Cause of biliary obstruction was pancreatic cancer in seven patients, two patients had carcinoma gallbladder with mid-CBD block due to compression by metastatic lymph nodes, and one patient had ampullary carcinoma. All the patients had inaccessible papilla due to tumor infiltration of the duodenum. Mean bilirubin value was $16.4 \mathrm{mg} / \mathrm{dL}( \pm 3.2 \mathrm{mg} / \mathrm{dL})$. The mean age was $58.6( \pm 4.2)$.

Technical success was $100 \%$. In all the patients, wire-guided 6 Fr cystotome was used for dilatation; mean procedure time was $32 \mathrm{~min}( \pm 12 \mathrm{~min})$. No immediate procedure-related complication was noticed. Functional success was $90 \%$. Jaundice improved after the procedure in all the patients except one who had liver metastasis. Bilirubin value decreased to $1.8 \mathrm{mg} / \mathrm{dL}(1.4 \mathrm{mg} / \mathrm{dL})$ at 1-month follow-up. After a mean follow-up of 8 months ( \pm 3 months), survival was $60 \%$, four patients died because of the underlying malignancy. Two patients had stent migration in duodenal lumen at 3 and 4 months after the initial procedure, which was taken out, and plastic stent was placed through the patent choledochoduodenal fistula [Table 2].

\section{Discussion}

We found EUS-CDS safe and efficacious in patients with inaccessible papilla. EUS-guided cholangiography was first described by Wiersema et al. in 1996, and first EUS-guided biliary drainage was described by Giovannini et $a l .{ }^{\left[{ }^{[9}\right.}$ in 2001 , and since that time many reports of EUS-guided biliary drainage have been published. EUS-guided biliary drainage is evolving technique, which needs comparison with existing modalities of biliary drainage. Success rate and complications of EUS-guided biliary drainage in lower end CBD block are comparable to ERCP. ${ }^{[10]}$ In the large retrospective series by Dhir et al., success rate and complication rate

\begin{tabular}{lclcl}
\hline \multicolumn{5}{c}{ Table 1: Baseline characteristics of included patients } \\
\hline $\begin{array}{l}\text { Patient } \\
\text { number }\end{array}$ & $\begin{array}{c}\text { Age } \\
\text { (years) }\end{array}$ & Gender & $\begin{array}{c}\text { Mean bilirubin } \\
\text { (mg/dl) }\end{array}$ & $\begin{array}{l}\text { Diagnosis } \\
\text { (carcinoma) }\end{array}$ \\
\hline 1 & 66 & Male & 19.2 & Pancreatic \\
2 & 61 & Female & 13.8 & Pancreatic \\
3 & 60 & Female & 11.6 & Gall bladder \\
4 & 53 & Male & 20.4 & Ampullary \\
5 & 64 & Male & 16.2 & Pancreatic \\
6 & 56 & Female & 21 & Pancreatic \\
7 & 56 & Male & 13.4 & Gall bladder \\
8 & 52 & Female & 19.6 & Pancreatic \\
9 & 60 & Male & 15.4 & Pancreatic \\
10 & 58 & Male & 13.6 & Pancreatic \\
\hline
\end{tabular}

Table 2: Outcome of endoscopic ultrasound choledochoduodenostomy

\begin{tabular}{lccl}
\hline $\begin{array}{l}\text { Patient } \\
\text { number }\end{array}$ & $\begin{array}{c}\text { Technical } \\
\text { success }\end{array}$ & $\begin{array}{c}\text { Functional } \\
\text { success }\end{array}$ & $\begin{array}{l}\text { Long-term } \\
\text { complications }\end{array}$ \\
\hline 1 & Yes & Yes & No \\
2 & Yes & Yes & No \\
3 & Yes & Yes & No \\
4 & Yes & Yes & No \\
5 & Yes & Yes & Stent migration \\
6 & Yes & Yes & No \\
7 & Yes & Yes & No \\
8 & Yes & Yes & Stent migration \\
9 & Yes & No & No \\
10 & Yes & Yes & No \\
\hline
\end{tabular}

for EUS-guided drainage (choledochoduodenostomy and antegrade procedures) were $93.26 \%$ and $8.65 \%$, respectively, which were similar to ERCP group. Similarly, EUS-guided drainage has been compared with PTBD. A study by Artifon et al. found similar technical, functional success, complications, and quality of life score in patients treated with PTBD and EUS-CDS. Nearly $33 \%$ of patients treated with PTBD had external drain initially which was internalized at follow-up. ${ }^{[11]}$ However, Bapaye et al. reported higher success rate $(95 \%$ vs. $46 \%)$ and lower complication rate (20\% vs. $46 \%)$ with EUS-guided drainage as compared to PTBD. ${ }^{[12]}$ EUS-guided procedures include rendezvous procedure or drainage procedures which can be performed by either transmural (choledochoduodenostomy or hepaticogastrostomy [HPG]) or antegrade approach. Rendezvous procedure was not feasible in our cohort of patients due to the inaccessible papilla. EUS-guided choledochoduodenostomy and HPG were compared in the recent randomized controlled trial, with comparable technical and clinical success. ${ }^{[13]}$ Artifon et al. reported technical success rates of HPG and choledochoduodenostomy (CD) in $96 \%$ and $91 \%$ of patients, respectively, and clinical success rates were $91 \%$ and $77 \%$, respectively. The adverse events 
were $20 \%$ for the HPG group and $12.5 \%$ for the CD group. Dhir et al. ${ }^{[14]}$ reported $95.6 \%$ success rate of EUS-guided biliary drainage and complication rate was $20.6 \%$. Complications were significantly higher for the transhepatic route compared to the transduodenal route $(30.5 \%$ vs. $9.3 \%, P=0.03)$. In the present study, all the patients underwent choledochoduodenostomy. Steps of EUS-CDS are CBD puncture, tract dilatation, and stent deployment. Initial CBD puncture should be done with $19 \mathrm{G}$ needle, either of FNA needle with beveled tip or access needle with blunt tip. The theoretical benefit with access needle is less shearing of guide wire; however, comparative studies are not available. Needle knife, biliary balloon, 4 and $6 \mathrm{Fr}$ cannulas, and $6 \mathrm{Fr}$ cystotome are commonly used accessories for dilatation. The use of needle knife has been associated with serious adverse events of bile leak and perforations, ${ }^{[15]}$ Park et al. reported this complication in $11 / 55(20 \%)$ of the patients undergoing EUS-guided drainage, and most were reported to the use of needle knife (9/11). Similarly, Dhir et al. reported perforation in two of the three patients where needle knife was used. In this study, 6 Fr cystotome was used for dilatation in all the patients, and no complication related to bile leak or pneumoperitoneum was reported. After creation of fistula, either plastic or metal stent can be used. Although direct comparative studies are not available, metal stent may be associated with lesser bile leak, pneumoperitoneum and bleed, due to mechanical compression and tight apposition of stent against the wall of fistula, moreover because of larger diameter, occlusion rate may be lower and decline in bilirubin may be sharper. Only covered stents should be used during choledochoduodenostomy to reduce the risk of bile or air leak, however, covered stent may increase the risk of stent migration. In the present study, two patients had stent migration during the follow-up, which was removed endoscopically, but at that time, we could notice patent fistula through which plastic stent was placed.

Limitation of the study is small sample size and data are limited to patients from a single center, which may reduce its generalizability. However, the strength of the study is that we have chosen similar patients in our study, and all the patients underwent biliary drainage with a similar technique, with similar set of accessories used in all the patients. Hence, we can conclude that in group of patients with mid and lower end CBD block and inaccessible papilla, EUS-guided choledochoduodenostomy is efficacious and safe technique.

\section{Financial support and sponsorship}

Nil.

\section{Conflicts of interest}

There are no conflicts of interest.

\section{REFERENCES}

1. Schöfl R. Diagnostic endoscopic retrograde cholangiopancreatography. Endoscopy 2001; 33:147-57.

2. Park DH, Koo JE, Oh J, Lee YH, Moon SH, Lee SS, et al. EUS-guided biliary drainage with one-step placement of a fully covered metal stent for malignant biliary obstruction: A prospective feasibility study. Am J Gastroenterol 2009;104:2168-74.

3. Bories E, Pesenti C, Caillol F, Lopes C, Giovannini M. Transgastric endoscopic ultrasonography-guided biliary drainage: Results of a pilot study. Endoscopy 2007;39:287-91.

4. Winick AB, Waybill PN, Venbrux AC. Complications of percutaneous transhepatic biliary interventions. Tech Vasc Interv Radiol 2001;4:200-6.

5. Wiersema MJ, Sandusky D, Carr R, Wiersema LM, Erdel WC, Frederick PK, et al. Endosonography-guided cholangiopancreatography. Gastrointest Endosc 1996;43:102-6.

6. Terruzzi V, Radaelli F, Meucci G, Minoli G. Is the supine position as safe and effective as the prone position for endoscopic retrograde cholangiopancreatography? A prospective randomized study. Endoscopy 2005;37:1211-4.

7. Sharma M, Pathak A, Shoukat A, Rameshbabu CS, Ajmera A, Wani ZA, et al. Imaging of common bile duct by linear endoscopic ultrasound. World J Gastrointest Endosc 2015;7:1170-80.

8. ASGE Technology Committee, Siddiqui UD, Banerjee S, Barth B, Chauhan SS, Gottlieb KT, et al. Tools for endoscopic stricture dilation. Gastrointest Endosc 2013;78:391-404.

9. Giovannini M, Moutardier V, Pesenti C, Bories E, Lelong B, Delpero JR, et al. Endoscopic ultrasound-guided bilioduodenal anastomosis: A new technique for biliary drainage. Endoscopy 2001;33:898-900.

10. Dhir V, Itoi T, Khashab MA, Park DH, Yuen Bun Teoh A, Attam R, et al. Multicenter comparative evaluation of endoscopic placement of expandable metal stents for malignant distal common bile duct obstruction by ERCP or EUS-guided approach. Gastrointest Endosc 2015;81:913-23.

11. Artifon EL, Aparicio D, Paione JB, Lo SK, Bordini A, Rabello $\mathrm{C}$, et al. Biliary drainage in patients with unresectable, malignant obstruction where ERCP fails: Endoscopic ultrasonography-guided choledochoduodenostomy versus percutaneous drainage. J Clin Gastroenterol 2012;46:768-74.

12. Bapaye A, Dubale N, Aher A. Comparison of endosonography-guided vs. Percutaneous biliary stenting when papilla is inaccessible for ERCP. United European Gastroenterol J 2013;1:285-93.

13. Artifon EL, Marson FP, Gaidhane M, Kahaleh M, Otoch JP. Hepaticogastrostomy or choledochoduodenostomy for distal malignant biliary obstruction after failed ERCP: Is there any difference? Gastrointest Endosc 2015;81:950-9.

14. Dhir V, Artifon EL, Gupta K, Vila JJ, Maselli R, Frazao M, et al. Multicenter study on endoscopic ultrasound-guided expandable biliary metal stent placement: Choice of access route, direction of stent insertion, and drainage route. Dig Endosc 2014;26:430-5.

15. Park DH, Jang JW, Lee SS, Seo DW, Lee SK, Kim MH, et al. EUS-guided biliary drainage with transluminal stenting after failed ERCP: Predictors of adverse events and long-term results. Gastrointest Endosc 2011;74:1276-84. 